Revista Universo Contábil, ISSN 1809-3337

FURB, v. 5, n. 2, p. 58-70, abr./jun., 2009

doi:10.4270/ruc. 2009213

Disponível em www.furb.br/universocontabil

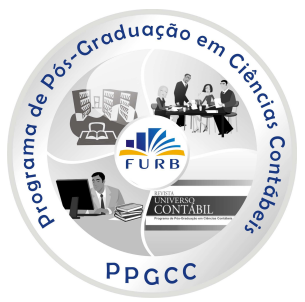

\title{
IMPACTO DA EVOLUÇÃO FUTURA DOS PREÇOS DOS OVOS NO DESEMPENHO DE UMA GRANJA DE AVES DE POSTURA COMERCIAL*
}

\section{IMPACT OF THE EVOLUTION OF FUTURE EGG PRICES ON THE PERFORMANCE OF A COMMERCIAL EGG PRODUCING OPERATION}

José Renato Auler

Mestre em Ciências Contábeis pela FUCAPE

Endereço: Av. Fernando Ferrari, 1358

CEP: 29075-505 - Vitória/ES - Brasil

E-mail: renatoauler@bol.com.br

Telefone: (27) 4009-4444

\section{Aridelmo José Campanharo Teixeira}

Doutor em Ciências Contábeis pela FEA/USP

Professor da FUCAPE Business School

Endereço: Av. Fernando Ferrari, 1358

CEP: 29075-505 - Vitória/ES - Brasil

E-mail: aridelmo@fucape.br

Telefone: (27) 4009-4444

Arilda Magna Campagnaro Teixeira

Doutora em Economia pela UFRJ Professora da FUCAPE Business School Endereço: Av. Fernando Ferrari, 1358 CEP: 29075-505 - Vitória/ES - Brasil

E-mail: arildat@fucape.br

Telefone: (27) 4009-4444

\section{Ézio Carlos Silva Baptista}

Doutor em Direito pela PUC/SP Professor da FUCAPE Business School Endereço: Av. Fernando Ferrari, 1358 CEP: 29075-505 - Vitória/ES - Brasil E-mail: ezio@fucape.br Telefone: (27) 4009-4444

Artigo recebido em 29.09.2008. Revisado por pares em 06.11.2008. Reformulado em 05.12.2008. Recomendado em 15.12.2008 por Ilse Maria Beuren (Editora). Publicado em 30.06.2009. Organização responsável pelo periódico: FURB. 


\section{RESUMO}

Objetiva-se com este estudo identificar com base no método de opções reais, uma fronteira de preços mínimos de uma caixa de ovos ao longo da vida útil da ave, utilizando duas séries históricas de preços. Em um cenário dinâmico e repleto de incertezas, a flexibilidade gerencial é um condicionante essencial ao desempenho do produtor. A flexibilidade na administração pode ser a opção de esperar mais um período para vender a um preço eventualmente maior, o que significa dizer que o produtor possui uma opção real. Trata-se este estudo de uma pesquisa empírica, que apresenta, sob a incerteza da evolução futura de preços, uma fronteira dos preços mínimos de uma caixa de ovos, aos quais ainda é lucrativo manter a ave por mais um período, ao invés de abatê-la imediatamente durante sua vida útil isto é, não exercer a opção real. Para a construção desta fronteira, utiliza-se o método da programação dinâmica. Observa-se que, aos preços de dezembro de 2005, se o preço da caixa de ovos caísse para menos de $\mathrm{R} \$ 16,00$ no início da vida comercial da ave, não valeria a pena mantê-la. O resultado principal pode ser resumido em uma fronteira de preços mínimos de uma caixa de ovos, cuja interpretação é relativamente imediata: se o preço naquele instante de tempo é inferior ao da fronteira, vale a pena vender prontamente a ave do que esperar mais uma semana, pois a evolução esperada dos preços não é recompensadora.

Palavras-chave: Estudo de caso. Granja de ovos. Programação dinâmica.

\section{ABSTRACT}

The aim of this case study is to apply the real options method to identify a minimum price frontier for a box of eggs over the useful life of a laying hen, using two historical price series. In a dynamic scenario filled with uncertainties, management flexibility is an essential conditioning factor to a producer's performance. Management flexibility can be the option to wait to sell at a potentially higher price, meaning the producer has a real option. The study is empirical, presenting the evolution, under the uncertainty of the future price of eggs, of a minimum cost frontier of a box of eggs for which it is still profitable to maintain the laying hen for an additional period instead of slaughtering it before the end of its useful life meaning not to exercise the real option. To construct this frontier, we used the dynamic programming method. We observe that at the prices of December 2005, if the price of a box of eggs had fallen to less than $R \$ 16.00$ at the start of a laying hen's commercial life, the option for slaughtering it would not have been rational. The main result can be summarized in a minimum price frontier for a box of eggs, whose interpretation is immediate: if the price at that moment in time is less than the frontier, it is worth selling the hen immediately than waiting another week, since the expected evolution of prices is not compensatory.

Keywords: Case study. Egg producing. Dynamic programming.

\section{INTRODUÇÃO}

Em um mundo dinâmico e repleto de incertezas, a flexibilidade é um condicionante essencial ao desempenho do produtor. Mais especificamente, a flexibilidade gerencial consiste em uma série de opções reais que representam formas de adaptação às mudanças de cenário, como por exemplo, alterações de demanda ou de condições de competição no mercado. 
Copeland e Antikarov (2001, p. 6) definem uma opção real como "o direito, mas não a obrigação, de empreender uma ação (por exemplo, adiar, expandir, contrair ou abandonar) a um custo predeterminado que se denomina preço de exercício, por um período preestabelecendo (a vida da opção)". Conseqüentemente, a opção é um contrato que dá a seu dono o direito, mas não a obrigação de exercitar este direito.

Assim, em um período em que a evolução recente foi de queda dos preços domésticos dos produtos agrícolas, é fundamental antecipar sua evolução futura para o bom desempenho do produtor. Dito de forma simples, isto significa que o dilema atual de um produtor de ovos consiste em saber se vale a pena esperar uma retomada de alta dos preços (e incorrer em mais custos) ou antecipar a continuação da queda e abater a ave (livrando-se assim dos custos de produção respectivos). Daí surge a seguinte questão de pesquisa: com base no método de opções reais, este artigo calcula uma fronteira de preços de uma caixa de ovos (isto é, os preços aos quais o produtor fica indiferente entre as duas alternativas) ao longo da vida útil da ave, utilizando duas séries históricas de preços: preços na granja e preços baseados na Fundação Getúlio Vargas (FGV).

Note que esta fronteira de preços é distinta daquela gerada pelo método do valor presente líquido (VPL), que consistiria basicamente em calcular os preços a cada instante para o qual o VPL é nulo. A diferença básica é que no método de opções reais, a flexibilidade é considerada e, portanto, incorporada no valor presente líquido. Dito de outra forma, a capacidade de adaptação requer uma regra para um "valor presente líquido (VPL) expandido" que reflita tanto o VPL tradicional (estático), quanto o valor da flexibilidade gerencial (TRIGEORGIS, 1996).

O método do Valor Presente Líquido (VPL) é uma técnica utilizada para calcular o valor econômico de um projeto, determinado pelo valor líquido dos fluxos de caixa esperados descontados por uma taxa de juros apropriada.

Diante do exposto, o objetivo deste estudo foi identificar com base no método de opções reais, uma fronteira de preços mínimos de uma caixa de ovos ao longo da vida útil da ave, utilizando duas séries históricas de preços. Assim, trata-se uma pesquisa empírica que se utilizou de um estudo de caso em uma granja, na qual foram aplicadas entrevistas aos gestores para a coleta dos dados. Na seqüência, foram inseridos na programação dinâmica para, com base em testes estatísticos, responder ao objetivo deste estudo.

\section{ASPECTOS GERAIS DA AVICULTURA BRASILEIRA}

A avicultura brasileira, assim como o agronegócio em geral, tem desempenhado um papel importante dentro da economia brasileira nos últimos anos. Segundo o relatório da UBA (2005), a avicultura tem crescido mais do que a economia em geral e tem representado um importante papel nas exportações agrícolas do país.

Em 2003, o plantel de poedeiras comerciais atingiu 79 milhões de aves. A produção de ovos alcançou 62,8 milhões de caixas de 30 dúzias, totalizando assim a oferta de 22,6 bilhões de ovos. O consumo per capita atingiu 127 ovos, sinalizando um grande potencial de crescimento de demanda no mercado interno em relação a outros países: o consumo per capita anual dos Estados Unidos é de cerca de 260 unidades, enquanto no Japão é de aproximadamente 340 unidades e na China, em torno de 300 unidades (GENÉTICA, 2002, p. 27).

O Brasil é um dos países que mais avançaram em tecnologia avícola nas últimas décadas. De acordo com Furtado et al. (2001, p. 655), esse avanço é fruto primordialmente do melhoramento genético das aves de postura, potencializando a produção das linhagens existentes. O cruzamento das raças gera galinhas híbridas cuja produção ultrapassa 330 ovos 
em 80 semanas de idade. Para efeito de comparação, este número representa mais do que o dobro obtido na década de 40, quando uma ave alojada com aproximadamente 70 semanas produzia 134 ovos, ou mesmo há cerca de 20 anos, quando a produção por ave alojada estava em torno de 260 ovos, conforme ilustra a Figura 1.

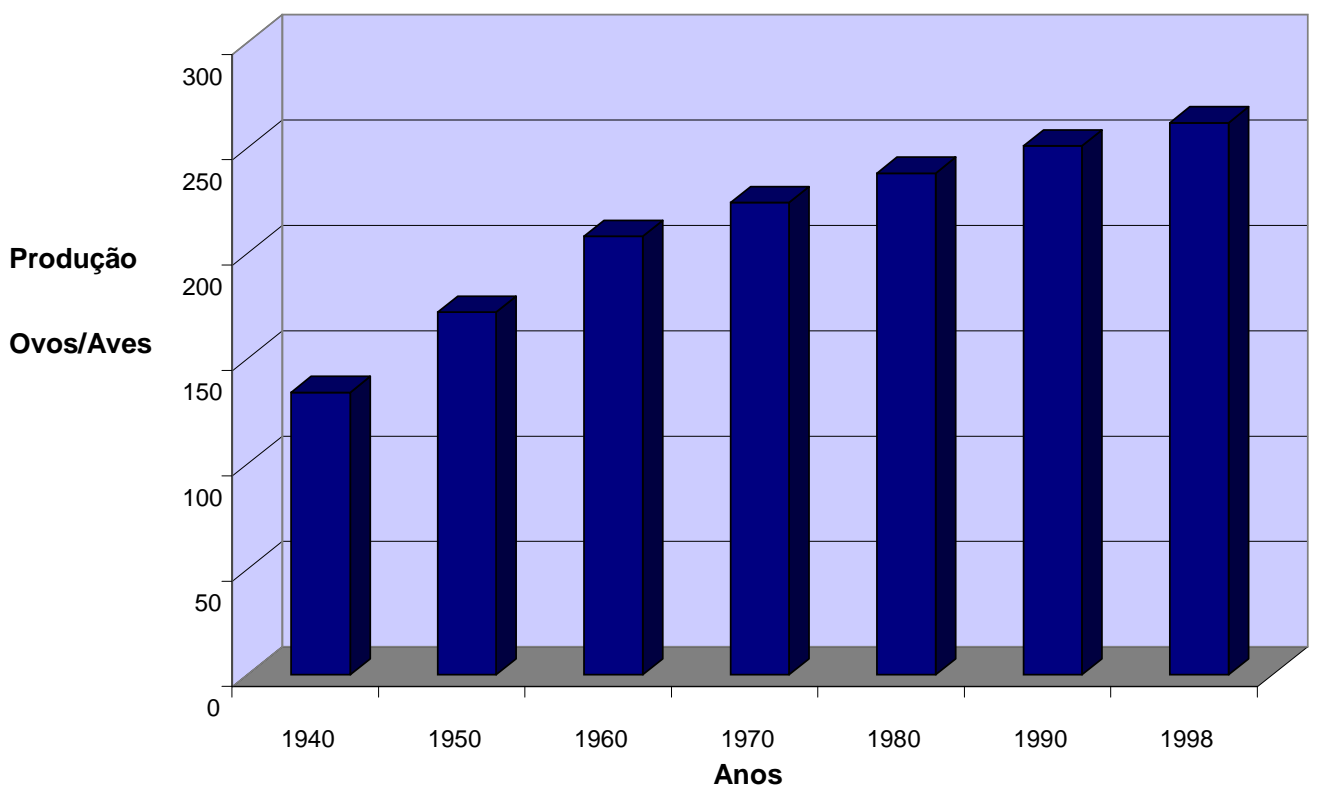

Figura 1 - Produção de ovos por ave durante o ciclo de vida na postura em 2003 Fonte: UBA Relatório Anual, 2003/2004.

Segundo Figueiredo (2003, p. 51), as evoluções genéticas das poedeiras produziram aves mais produtivas, com menor peso corporal e baixo consumo de ração. A ampliação da produtividade, no entanto, vem chegando ao seu limite e as pesquisas de melhoramento genético já trabalham há algum tempo com outros aspectos produtivos, como a diminuição da mortalidade, a redução da agressividade entre as aves, a padronização do ovo obtido durante o período produtivo da ave e o aperfeiçoamento dos índices de conversão alimentar.

Outro fator relevante na produção de poedeiras é o manejo; prática cujo intuito é melhorar a relação entre as aves e o seu ambiente de criação, pois mudanças bruscas no manejo podem gerar estresse nas aves, com impacto significativo na produtividade.

A manutenção de um bom ambiente de criação está relacionada a três fatores principais: temperatura, umidade relativa e ventilação, sendo que as aves têm exigências diferentes conforme a idade. $\mathrm{Na}$ fase inicial de cria (que vai até a quarta semana), a ave é exigente com o calor. Na fase seguinte (da quinta semana até a décima nona semana), chamada de recria, a ave passa por uma transformação e adaptação ao ambiente, passando da exigência de calor à fadiga pela alta temperatura. Na vigésima semana, inicia-se o ciclo de postura comercial, quando fica patente uma correlação inversa entre temperatura e a produtividade: a ocorrência de altas temperaturas ambientais provoca queda no consumo de ração, pois a ave tenta reduzir seu metabolismo para, com isto, diminuir o calor metabólico. Como consequiência, há uma menor produção, menor peso dos ovos e pior qualidade de casca e clara.

Por fim, a questão da sanidade é outro fator que afeta a produtividade da granja. A forma mais eficiente de garantir uma boa sanidade é prevenir a entrada de agentes de doenças em uma granja de postura comercial, por meio de um adequado alojamento da ave, educação 
sanitária, sistema de registro, limpeza, lavagem e desinfecção, alimentação e água de bebida, lixos, resíduos, cadáveres de aves, esterco, roedores e insetos. Em caso de alguma suspeita, deve-se fazer o diagnóstico precoce, para que se possa atender prontamente e controlar o foco no ponto de aparecimento, impedindo a disseminação para outras granjas (ISBIZUKA, 2003, p. 52).

O processo de modernização das granjas passou também pela melhoria tanto das instalações de criação como, principalmente, das práticas gerenciais. Hoje, mais de 15 milhões de aves se encontram alojadas em instalações modernas, com alta densidade de alojamento. Por outro lado, ainda há granjas convencionais que aparentemente possuem um custo inicial mais baixo e ainda exigem uma maior necessidade de mão-de-obra e maior espaço físico. São instalações ainda viáveis para os pequenos produtores principalmente os de agricultura de base familiar.

Como estas instalações exigem maior custo de implantação, necessidade de grandes lotes de reposição e melhor controle sanitário, foi essencial um salto de qualidade no gerenciamento da granja, o que implicou redução significativa do percentual de ovos não aproveitáveis, menor custo de mão-de-obra, menor desperdício de ração e maior controle dos fatores ambientais.

\section{A PRODUÇÃO AVÍCOLA DAS GRANJAS KERCKHOFF}

A estratégia da pesquisa foi o estudo do caso realizado na Granja Kerckhoff, a maior produtora do estado do Espírito Santo. Localizada no município de Santa Maria de Jetibá, seu parque de produção é $70 \%$ automatizado e 30\% convencional. O sistema automatizado permite maior uniformidade no controle, na distribuição e dosagem da ração e na eliminação de desperdícios, o que não é garantido pelo sistema convencional.

A produção é basicamente gerada por 1,1 milhão de aves da raça Hy-Line W36 (há mais 200 mil aves em formação). Esta raça foi escolhida pela granja por apresentar uma melhor adaptação ao clima local, baixo consumo de ração e facilidade no manejo.

O período de postura da raça $H y$-Line W36 começa com aproximadamente 20 semanas e costuma ir até 80 semanas. Até 60 semanas, uma ave tem uma produção aproximada de 234 a 240 ovos e com 80 semanas, a produção atinge de 338 a 346 ovos. A média de consumo de ração ao dia de 18 semanas a 80 semanas é, em média, de 94g/ave/dia (HY-LINE VARIETY W36, p. 4).

A "ave branca $1^{\circ}$ ciclo e sem muda" é o primeiro ciclo de postura normal da ave. Muda é a troca de penas da ave, fase de descanso e renovação para melhoramento da taxa de postura e a qualidade de casca do ovo. Essa fase vai da vigésima semana até a septuagésima quinta semana, aproximadamente. A "ave branca com muda" ou segundo ciclo de postura, geralmente começa com 76 semanas e vai até 120 semanas, aproximadamente, quando poderá ser descartada para abate. A fase da muda forçada tem como característica a redução do consumo de alimento, a perda de penas, a regressão acentuada no peso corporal e no trato reprodutivo, a ave fica, geralmente, dez dias sem comer e sem luz artificial, sobrevivente somente com água, visando a sua renovação e descanso, para melhorar sua taxa de postura.

\section{METODOLOGIA PARA O CÁLCULO DA FLEXIBILIDADE GERENCIAL}

Para uma melhor compreensão do conceito de flexibilidade gerencial e da diferença entre os métodos do valor presente líquido (VPL) e a teoria das opções reais (TOR) é interessante iniciar com um exemplo mais simples da decisão operacional semanal do produtor de ovos de uma ave de postura. 


\subsection{Um exemplo simples}

Suponha que uma galinha viva eternamente. Seu proprietário tem apenas duas escolhas: ou vende a galinha hoje ou vende na semana seguinte. Se não a vender neste período, não poderá vendê-la mais. Assim, neste exemplo, foi utilizada a receita presente no caso da venda e a receita futura que seria a opção da próxima semana.

Caso o produtor venda a ave imediatamente, ele abre mão de toda a receita da venda de ovos mais a receita de descarte da ave na próxima semana. Se o produtor optar por continuar com a ave por mais uma semana, ele pagará o custo semanal de manutenção da ave e receberá, ao fim de uma semana, o valor dos ovos da galinha e poderá novamente decidir se vende a ave. Se continuar com a galinha, ele recebe o valor descontado das receitas com vendas de ovos. Se vender a ave, o produtor recebe o valor de abate da ave.

Portanto, a ave põe 5 ovos por semana e o preço corrente de cada unidade corresponde a $\$ 0,12$. Daqui a uma semana, com probabilidade de $50 \%$ o preço pode subir para $\$ 0,18$ e permanecer neste patamar para sempre, e com probabilidade de $50 \%$, o preço pode cair para $\$ 0,06$ e continuar assim indefinidamente. $O$ custo da ave por semana é constante e igual a $\$ 0,35$. O valor do descarte da ave é igual a $\$ 1,00$. Admite-se que a taxa de desconto apropriada é igual a $20 \%$ ao ano.

Com estes dados, o avicultor deveria vender a ave agora ou seria melhor esperar mais uma semana e ver se os preços sobem ou descem? Se o avicultor vender a ave hoje, recebe $\$ 1$ e nada mais. Pode-se verificar quanto o avicultor recebe, caso ele postergue a venda da ave.

Pelo método tradicional do VPL e notando-se que o preço futuro esperado é sempre $\$ 0,12=(0,5 * \$ 0,06+0,5 * \$ 0,18)$ temos que o fluxo esperado semanal é igual a $\$ 0,25$ (pois, $\mathrm{E}(\mathrm{FC})=(0,12) * 5-0,35=0,25)$. Assim, o valor presente líquido de manter a ave é igual a $\$ 1,25(\mathrm{VP}(\mathrm{E}(\mathrm{FC}))=\mathrm{E}(\mathrm{FC}) / \mathrm{r}=0,25 / 0,20=1,25)$. Conseqüentemente, como o VPL de ficar com a ave é maior do que o valor de descarte da ave, vale a pena ficar com a ave e seu valor é igual a $\$ 1,25$.

Portanto, o valor da ave $\left(\mathrm{F}_{0}\right)$ é dado por:

$$
\mathrm{F}_{0}=\max \{V P(E(F C)), 1\}
$$

Agora suponha que a venda só ocorra em $t=1$. Há duas possibilidades: ou o preço subir ou o preço cair. No primeiro caso, podemos calcular o valor da ave de forma análoga a que foi feita anteriormente. Chame de $\mathrm{F}_{1 \mathrm{u}} \mathrm{o}$ valor da ave quando o preço sobe em $\mathrm{t}=1$. Neste caso, o fluxo de caixa semanal $\left(\mathrm{FC}_{1 \mathrm{u}}\right)$ é igual a $\$ 0,55\left(\mathrm{FC}_{1 \mathrm{u}}=(0,18 * 5-0,35)=0,55\right)$ e o valor de $\mathrm{F}_{1 \mathrm{u}}$ é igual a $\$ 3,30\left(\mathrm{~F}_{1 \mathrm{u}}=\mathrm{FC}_{1 \mathrm{u}} *(1+\mathrm{r}) / \mathrm{r}=0,55^{*}(1,2) / 0,2=3,30\right)$ que é maior do que o valor de descarte da ave. Portanto, o valor da ave em $t=1$ quando o preço sobe é $\mathrm{F}_{1 \mathrm{u}}=\$ 3,30$.

No caso em que o preço desce, temos que $\mathrm{FC}_{1 \mathrm{~d}}=0,5^{*}(0,06 * 5-0,35)<0$ e fica evidente que o melhor é vender a ave. Portanto, o valor da ave quando o preço cai é $F_{1 d}=\$ 1,00$.

Assim, o valor esperado do valor da ave no período 1 é igual a $E\left(F_{1}\right) /(1+r)=\left(0,5^{*} F_{1 u}\right.$ $\left.+0,5^{*} \mathrm{~F}_{1 \mathrm{~d}}\right) /(1+\mathrm{r})=(2,15) /(1,2)=1,79$.

No momento $\mathrm{t}=0$, o avicultor tem duas escolhas: vender a ave e ganhar $\$ 1$ ou esperar e ganhar, em termos esperados, $\$ 1,79$. Portanto, o vendedor prefere ficar com a ave.

De forma mais geral, o maior entre os dois valores calculados acima é chamado de valor da oportunidade de investimento $\left(\mathrm{F}_{0}\right)$ que é dado por:

$$
F_{0}=\max \left\{V P(E(F C)), E F_{1} /(1+r)\right\}
$$


Por fim, como a flexibilidade é um direito e não uma obrigação, seu valor não pode ser negativo. Assim, o valor da flexibilidade $\left(\mathrm{V}_{0}\right)$ é o máximo entre 0 e a diferença entre o segundo termo e o primeiro termo da função máximo na equação (2), ou seja:

$$
V_{0}=\max \left\{E F_{1} /(1+r)-V P(E(F C)), 0\right\}
$$

Desta forma, $\mathrm{V}_{0}$ representa o valor de esperar mais um período. Evidentemente, o exemplo numérico apresentado é bastante simples, pois: (i) o produtor só pode vender a ave em dois momentos e (ii) há apenas duas possibilidades de evolução do preço: ou sobe ou desce e permanece nesta situação para sempre. De forma mais realista, o produtor pode vender a ave a qualquer momento durante sua vida útil e o preço pode evoluir de maneira mais complexa, o que acaba por influenciar o cálculo do valor da opção.

De qualquer forma, o exemplo acima é uma aplicação da metodologia da programação dinâmica que pode ser usada para analisar exemplos mais complexos, como descrito a seguir.

\subsection{Programação Dinâmica}

Inicialmente, é necessário desenvolver duas definições centrais na metodologia: a variável de estado e variável de controle. A variável de estado representa toda informação disponível para um agente até aquele momento do tempo. Representaremos esta variável por $\mathrm{X}$. A qualquer data ou período t, o valor atual da variável $X_{t}$ é conhecido, mas valores futuros de $X_{t+1}, X_{t+2}, \ldots$ são variáveis aleatórias. Suponha-se que esta variável siga um processo de Markov, isto significa que, todas as informações que são relevantes para a determinação da probabilidade de distribuição de valores futuros estão resumidas no estado atual de $\mathrm{X}_{t}$.

Especificamente, no caso do exemplo da ave, podemos dizer que toda informação relevante está embutida no preço do ovo, que será, dessa forma, a variável de estado.

A cada período de tempo e dada a respectiva variável de estado $X_{t}$, as escolhas disponíveis para a firma podem ser representadas pela variável de controle $u$. No exemplo da ave, a variável de controle era binária, isto é, o produtor poderia vender ou continuar com a ave. $\mathrm{O}$ valor de $\mathrm{u}_{\mathrm{t}}$ deve ser escolhido apenas usando as informações disponíveis naquele tempo, isto é, $\mathrm{X}_{t}$.

Antes de definir mais precisamente o problema de programação dinâmica, são necessárias algumas definições.

Seja $F_{t}\left(X_{t}, u_{t}\right)$ o resultado - o valor presente líquido esperado de todo o fluxo de caixa da firma - quando a firma toma todas as decisões (isto é, escolhe a variável de controle) de forma ótima a partir deste ponto em diante. Analogamente, em $t+1$, temos $F_{t+1}\left(X_{t+1}\right)$. Entretanto, em $\mathbf{t}$ este valor é aleatório e, desta forma, deve-se usar o valor esperado $E_{t}\left[F_{t+1}\left(X_{t+1}\right)\right]$. Este termo é chamado de valor de continuação. Defina, por fim, o fator de desconto entre quaisquer dois períodos como $1 /(1+r)$, onde $r$ é a taxa de desconto apropriada para o problema.

A aplicação da programação dinâmica consiste em dividir a seqüência de decisão do problema de otimização ao longo de um período $\mathrm{T}$ em duas partes, o período imediato e toda a continuação depois desta. No problema de nosso interesse, o objetivo do produtor da ave é escolher a sequiência de controles $\left\{\mathrm{u}_{\mathrm{t}}\right\}$ ao longo do tempo para maximizar o valor presente líquido esperado dos pagamentos.

A forma de resolução deste problema é baseada no chamado princípio da optimalidade de Bellman: uma política ótima de escolha da variável de controle tem a propriedade de que, 
qualquer que seja a ação inicial, as escolhas restantes constituem uma política ótima com respeito ao subproblema começando no estado que resulta das ações iniciais. Portanto, o valor ótimo das escolhas restantes $\mathrm{u}_{\mathrm{t}+1}, \mathrm{u}_{\mathrm{t}+2}, \ldots$ é somada ao chamado valor de continuação, onde somente resta o controle imediato $u_{t}$ para ser escolhido de forma ótima.

Portanto, o produtor escolherá $\mathrm{u}_{\mathrm{t}}$ para maximizar o valor recebido pela venda da ave $\left(\pi_{t}\left(X_{t}, u_{t}\right)\right)$ ou o valor de continuação descontado para $t$, e o resultado será, simplesmente, o valor $\mathrm{F}_{\mathrm{t}}\left(\mathrm{X}_{\mathrm{t}}\right)$. Assim, a equação de Bellman pode ser representada da seguinte forma:

$$
F_{t}\left(\mathrm{X}_{t}\right)=\max _{u_{t}}\left\{\pi_{t}\left(\mathrm{X}_{t}, u_{t}\right)+\frac{1}{1+r} E_{t}\left[F_{t+1}\left(\mathrm{X}_{t+1}\right)\right]\right\}
$$

Para reiterar, o primeiro termo do lado direito é o lucro imediato e o segundo termo constitui o valor de continuação, e a ação ótima deste período é aquela que maximiza a soma destes dois componentes.

Em um problema de muitos períodos com um horizonte de tempo finito fixo $\mathrm{T}$, o método da programação dinâmica consiste em resolver de trás para frente, isto é, começar no final do horizonte e trabalhar deste ponto para o presente.

No instante $\mathrm{T}$, devemos considerar ainda um pagamento final que depende do estado alcançado, denotado como função de pagamento final por $\Omega_{\mathrm{t}}\left(\mathrm{X}_{\mathrm{t}}\right)$. Assim, começando no final do horizonte a firma é dado um pagamento final $\Omega_{\mathrm{t}}\left(\mathrm{X}_{\mathrm{t}}\right)$, tem-se que no período imediatamente anterior,

$$
F_{T-1}\left(\mathrm{X}_{T-1}\right)=\max _{u_{T-1}}\left\{\pi_{T-1}\left(\mathrm{X}_{T-1}, u_{T-1}\right)+\left\{\frac{1}{1+r} E_{T-1}\left[F_{T}\left(\mathrm{X}_{T}\right)\right]\right\}\right.
$$

Com o valor da função em T-1 podemos resolver o problema de maximização para $\mathrm{u}_{\mathrm{T}-}$ 2, obtendo o valor da função $\mathrm{F}_{\mathrm{T}-2}\left(\mathrm{X}_{\mathrm{T}-2}\right)$, e assim, seqüencialmente até o instante t.

\subsection{Parada ótima}

Uma classe particular de problemas dinâmicos na programação é muito importante para aplicação desenvolvida neste artigo: problemas de parada ótima.

Nesse tipo de problema, a escolha em qualquer período é binária. Por exemplo, uma alternativa corresponde a parar o processo para fazer a venda da ave, e a outra implica na continuação (manutenção) da ave por mais um período, quando uma outra escolha binária semelhante estará disponível. Para uma empresa em más condições econômicas, a continuação pode dar eventualmente um fluxo de lucro negativo, e a venda imediata, a solução para reduzir este prejuízo, por exemplo.

Seja $\pi(\mathrm{x})$ o fluxo de lucro e $\Omega(\mathrm{x})$ a terminação (nesse caso, a venda da ave). Desta forma, a equação de Bellman pode ser escrita da seguinte maneira:

$$
F(x)=\max \left\{\Omega(x), \pi(x)+\frac{1}{1+r} E[F(x) \mid x]\right\}
$$

Dependendo do valor de x, o máximo do lado direito da equação será alcançado pela terminação (primeiro termo da função máximo da equação (6)), e para os outros valores de $x$ serão alcançados pela continuação (segundo termo da função máximo da equação (6)). Em geral, esta divisão poderia ser arbitrária: intervalos onde a terminação é ótima poderiam alternar com intervalos onde a continuação é ótima. No entanto, pode-se garantir condições 
para que haja um único corte $\mathrm{X}^{*}$, com terminação ótima de um lado e continuação do outro (DIXIT, PINDYCK, 1994).

Supondo que estas condições sejam atendidas, nosso trabalho se propõe a calcular o valor de $\mathrm{x}^{*}$ a cada momento dentro do horizonte de decisão. Esta variável, por sua vez, representa o maior prejuízo que o produtor admite ter para continuar ainda com a ave. Para um prejuízo ainda maior, o produtor vende a ave. Se o prejuízo for menor ou o produtor tiver lucros, ele continua com a ave.

\section{DECISÃO ÓTIMA NA PRODUÇÃO DE OVOS SOB INCERTEZA}

Pode-se aplicar a metodologia desenvolvida na seção anterior na questão central deste artigo, qual seja: é melhor vender a ave imediatamente ou esperar mais uma semana?

Suponha que a vida útil de uma galinha seja de 76 semanas. Após este período, a galinha é, por hipótese, necessariamente vendida para abate.

Considera-se um ciclo de produção de ovos por galinha mais simplificada no qual a produção começa a partir da $20^{\mathrm{a}}$ semana e permanece em 23 ovos a cada 4 semanas até o momento do abate da ave, desconsiderando a taxa de mortalidade das aves. Ou seja, o desgaste natural da galinha, com a redução gradativa de sua produção de ovos por semana e o potencial cuidado adicional que uma galinha mais velha requer são desconsiderados neste estudo. Estas hipóteses podem ser justificadas com base na Figura 2.

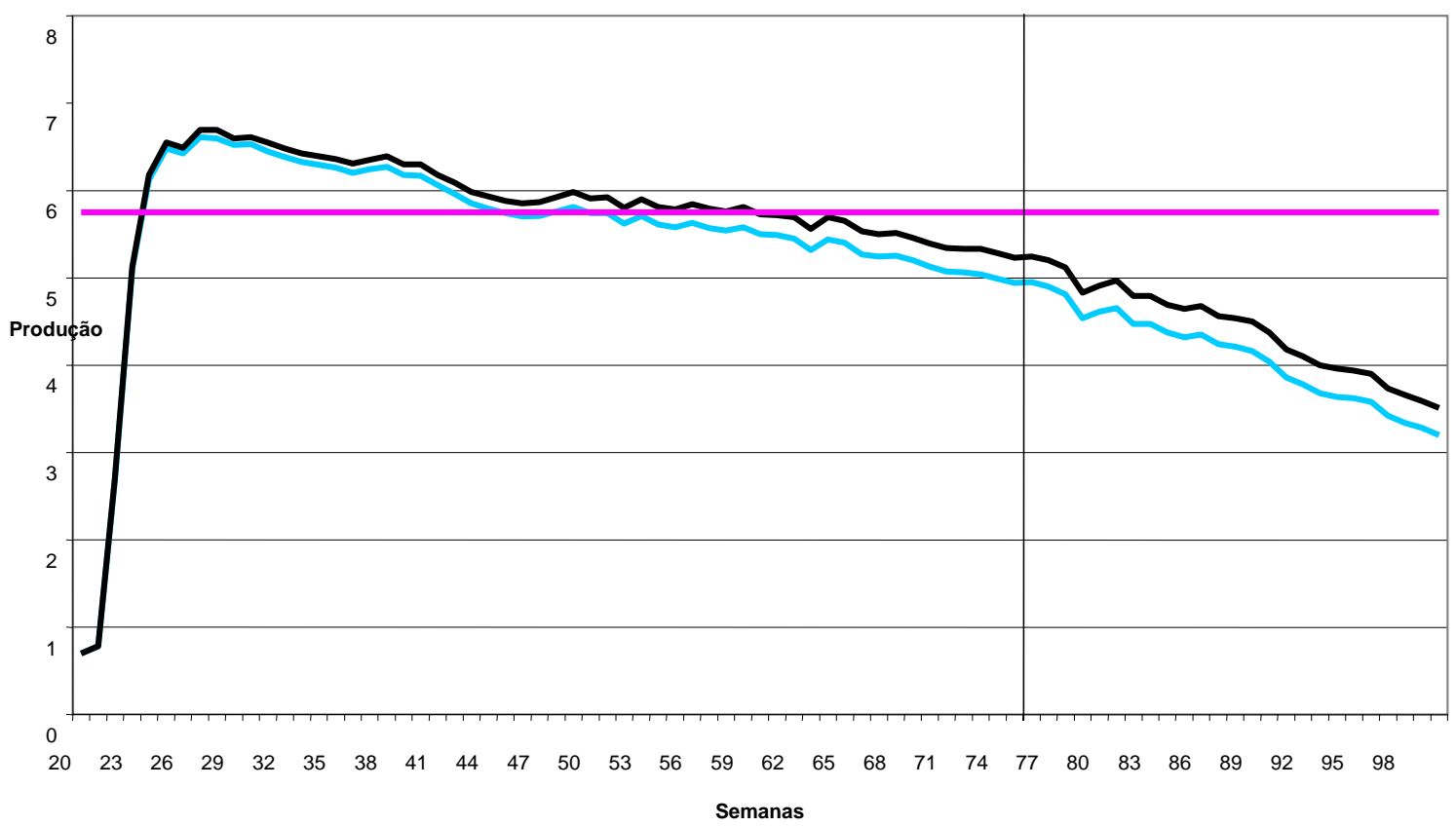

Figura 2 - Produção de ovos na granja Kerckhoff

Na Figura 2, temos a produção de ovos por semana na granja Kerckhoff, com desconto e sem desconto da mortalidade da ave. A cor azul representa a produção na granja sem descontar a mortalidade, a cor preta representa a produção na granja descontando a mortalidade e a cor rosa representa a produção hipotética do artigo.

Como podemos ver: (i) desconsiderar a mortalidade não é uma hipótese muito forte $\mathrm{e}$ (ii) a produção efetiva é apenas um pouco subestimada no início da vida útil da ave e um 
pouco superestimada no fim da vida útil da ave, quando comparada com nossa produção hipotética constante.

Adicionalmente, utilizou-se a hipótese de que a taxa de juros ajustada ao risco do negócio (r) é de $3 \%$ ao mês, que trata-se de uma taxa média praticada no mercado de negócios de igual risco custo semanal de manutenção das galinhas a preços de dezembro de 2005 foi estabelecido em $\mathrm{R} \$ 0,35$, com base nos números da granja Kerckhoff.

No início de cada semana (a partir da 19a semana), o problema do produtor pode ser resumido nas seguintes alternativas:

a) Vende a galinha e aufere imediatamente $\mathrm{R} \$ 1,00$;

b) Espera mais uma semana, quando os ovos são vendidos e se pode decidir novamente entre vender ou manter a ave por uma semana adicional. Neste caso, o produtor paga ainda um custo de manutenção da galinha naquela semana.

A qualquer duração de tempo da vida da ave, o avicultor pode vender a ave. Se o fluxo de lucro atual torna-se negativo, esta pode parecer uma alternativa atraente.

Pelo visto anteriormente, sabe-se que haverá uma curva-limite ou fronteira $x *(t)$ tal que se o lucro atual x cair abaixo desta curva, a ave deverá ser vendida.

Vamos supor que a variável x siga uma evolução dada por:

$$
d x=a d t+b d z
$$

Onde dz é o incremento de um processo Wiener. Para calcular os parâmetros a e b, usamos dois procedimentos:

(1) Deflacionou-se a série de preços semanais de 5,75 ovos (isto é, 23 ovos em 4 semanas por galinha), obtida da granja Kerckhoff, pelo IGP. Utilizamos ainda o IPCA como deflator, com resultado bem similares. Para obter a série de lucros, descontou-se o custo por galinha.

(2) Usou-se a série mensal de preços, obtida da FGV, deflacionou-se pelo IGP e calculou-se o lucro semanal dividindo o lucro mensal pelo número de semanas em cada mês.

Tabela 1 - Valores dos parâmetros

\begin{tabular}{c|c|c}
\hline Descrição & A & B \\
\hline Preços FGV & -0.0029 & 0.03505 \\
\hline Preços Granja & -0.0008 & 0.04436 \\
\hline
\end{tabular}

Para se obter uma solução numérica usou-se uma aproximação discreta do movimento Browniano.

\section{RESULTADOS}

Os resultados são apresentados de forma mais direta através de uma fronteira de preços ao invés de apresentar-se na forma de uma fronteira de lucros. No exemplo, isto é imediato, já que, por hipótese, a produção da galinha ao longo da sua vida e o custo semanal são constantes. Assim, a fronteira de lucros é substituída facilmente por uma fronteira de preços, fazendo-se as alterações apropriadas.

Conseqüentemente, a decisão do produtor será manter a galinha se o nível de preços dos ovos estiver acima da fronteira ou vendê-la, caso o nível de preços correntes esteja abaixo desta fronteira.

A Figura 3 representa a curva estimada do preço-limite. Para cada semana t, se o preço atual estiver acima desta curva, a ave será mantida, caso contrário, se o preço em um dado 
momento do tempo cair abaixo desta curva, a ave será vendida para abate com valor terminal de $\$ 1,00$.

Pode-se observar que a fronteira calculada com preços da granja Kerckhoff (Preço Santa Maria de Jetibá) fica sempre abaixo da fronteira calculada com os preços da FGV (Preço FGV), o que era esperado pelos parâmetros dos respectivos movimentos brownianos. Note ainda, que a diferença entre as duas curvas vai diminuindo ao longo da vida útil da ave. Além disto, se no início da vida comercial da ave, o preço for inferior a $\mathrm{R} \$ 16,00$ (preços de dezembro de 2005), isto significa que é melhor para o produtor vender imediatamente a ave, porque espera-se que a evolução futura de preços não compense os prejuízos atuais.

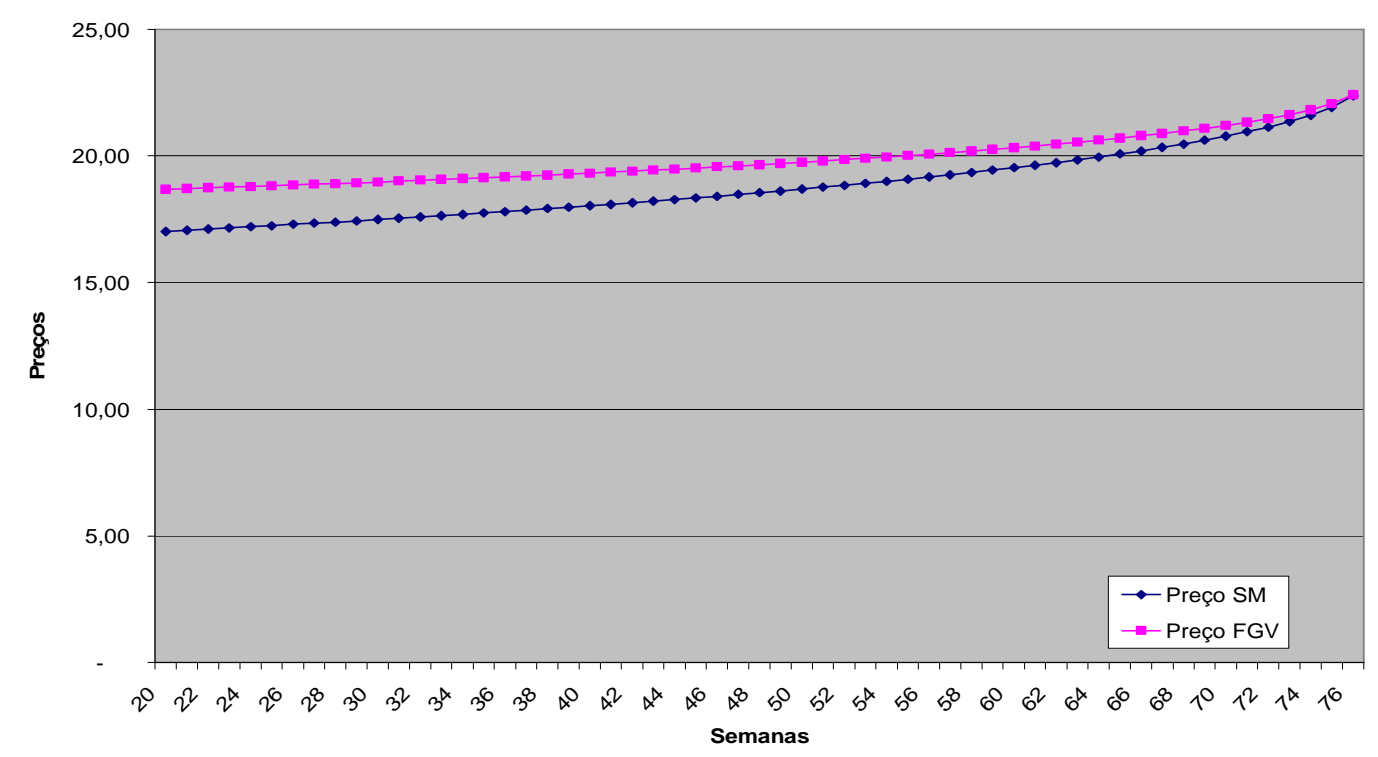

Figura 3 - Fronteira de Preços de uma caixa de ovos

(Base: dezembro de 2005)

\section{CONSIDERAÇÕES FINAIS}

A pesquisa procurou contribuir para a estrutura de tomada de decisões na atividade avícola de postura comercial, por meio de um modelo de avaliação de investimentos aplicando a teoria das opções reais. Assim, tratou-se de uma pesquisa empírica, que se utilizou de dados coletados in loco, na seqüência esses dados foram inseridos num modelo de programação dinâmica, no sentido de apresentar cenários de acordo com a tomada de decisão dos gestores.

O resultado principal pode ser resumido em uma fronteira de preços mínimos de uma caixa de ovos cuja interpretação é relativamente imediata, ou seja, se o preço naquele instante de tempo é inferior ao da fronteira, vale a pena vender prontamente a ave do que esperar mais uma semana, pois a evolução esperada dos preços não é recompensadora.

Dentre as limitações deste estudo vale destacar a forma com que os resultados da fronteira limite de preços encontrados nesta dissertação levaram em consideração a estrutura de custos da Granja Kerckhoff, em determinado período. Diante do exposto, esses resultados não podem ser considerados para decisão em outras estruturas. No entanto, a metodologia poderá ser reaplicada na busca de novas faixas de fronteiras limites de preços.

Portanto, em futuras pesquisas recomenda-se que o método utilizado neste artigo, naturalmente, poderá ser aplicado em outras decisões similares em que o produtor é um 
tomador de preços no seu respectivo mercado. Caso o gestor tenha algum poder de mercado, o método deste artigo deve ser modificado de maneira significativa.

\section{REFERÊNCIAS}

ALBUQUERQUE, R. Tópicos importantes na produção de poedeiras comerciais. Disponível em: <www.aviculturaindustrial.com.br>. Acesso em: 25 abr. 2005.

GENÉTICA. Revista Avicultura Industrial. Disponível em: <www.aviculturaindustrial.com.br>. Acesso em: 13 nov. 2004.

COELHO, A. A. D. Frango de corte e galinhas de postura. Revista Avicultura Industrial. v. 1102, n. 08, 2003.

COPELAND, Tom; ANTIKAROV, Vladimir. Opções Reais: um novo paradigma para reinventar a avaliação de investimentos. Rio de Janeiro: Campus, 2001.

DIXIT, A. K.; PINDYCK, R. S. Investment under uncertainty. New Jersey: Princeton, 1994.

FERNANDES, P. C. C. et al. Aditivos naturais: a segurança alimentar na produção avícola. Revista Aveworld, v. 2, n. 10, p. 48-51, 2004.

FIGUEIREDO, E. Evolução genética. Revista Avicultura Industrial, v. 1113, n. 6, 2003.

FURTADO, I. M. et al. Correlação entre medidas da qualidade da casca e perda de ovos no segundo ciclo de produção. Revista Ciência Agrotécnica, v. 25, n. 3, p. 654-660, maio/jun. 2001.

HY-LINE Variety W-36. Excelência genética: guia de manejo 2003-2005. Disponível em: <www.hylinedibrasil.com.br>. Acesso em: 5 jul. 2004.

INCAPER. Plano estratégico de desenvolvimento da agricultura capixaba. (PEDEAG), 2003.

ISBIZUKA, M. M. Medidas de biosseguridade na avicultura de postura. Revista Aveworld, v. 1, n. 03, p. 52-56, 2003.

KEMNA, A. G. Z. Case studies on real options. Financial Management, Autumn, p. 259-270, 1993. http://dx.doi.org/10.2307/3665943

KERCKHOFF, A. Granja Kerckhoff. 2004. Entrevista in loco concedida em 3 e 4 set. 2004.

MEDINA, J. R. Avanços na nutrição da poedeira moderna. Disponível em: <http://www.hylinedobrasil.com.br/files/6-palestra-CBNA.pdf>. Acesso em: 11 nov. 2004.

PREFEITURA MUNICIPAL DE SANTA MARIA DE JETIBÁ (PMSMJ). Secretária da Saúde. Disponível em: 〈www.pmsmj.gov.br〉. Acesso em: 15 out. 2004.

TRIGEORGIS, L. Real options: managerial flexibility and strategy in resource allocation. The MIT Press, 1996.

UNIÃO BRASILEIRA DE AVICULTURA (UBA). Relatório Anual 2003/2004. Disponível em: <www.uba.org.br>. Acesso em: 11 nov. 2004.

UNIÃO BRASILEIRA DE AVICULTURA (UBA). Relatório Anual 2005. Disponível em: <www.uba.org.br>. Acesso em: 15 out. 2005.

ULIANA, Argeo João. Entrevista concedida em 02/12/2004. Disponível em: <www.uba.org.br>. Acesso em: 15 out. 2005. 


\section{APÊNDICES}

Apêndice A - Custo de manutenção por ave/semana na Granja Kerckhoff em Santa Maria de Jetibá - ES

\begin{tabular}{|c|c|c|c|c|c|}
\hline mês/ano & semana & custo Ave/sem. & mês/ano & semana & custo Ave/sem \\
\hline Jan. 2004 & 20 & 0,264859689 & Set. 2004 & 57 & 0,362037793 \\
\hline Jan. 2004 & 21 & 0,262712386 & Set. 2004 & 58 & 0,360055585 \\
\hline Jan. 2004 & 22 & 0,289105335 & Out. 2004 & 59 & 0,358165674 \\
\hline Jan. 2004 & 23 & 0,313046633 & Out. 2004 & 60 & 0,355462115 \\
\hline Jan. 2004 & 24 & 0,338935889 & Out. 2004 & 61 & 0,366890906 \\
\hline Fev. 2004 & 25 & 0,345765610 & Out. 2004 & 62 & 0,359555043 \\
\hline Fev. 2004 & 26 & 0,345088008 & Out. 2004 & 63 & 0,360575827 \\
\hline Fev. 2004 & 27 & 0,359897384 & Nov. 2004 & 64 & 0,355324984 \\
\hline Fev. 2004 & 28 & 0,364416031 & Nov. 2004 & 65 & 0,357403998 \\
\hline Mar. 2004 & 29 & 0,370105072 & Nov. 2004 & 66 & 0,373968607 \\
\hline Mar. 2004 & 30 & 0,382690289 & Nov. 2004 & 67 & 0,360420646 \\
\hline Mar. 2004 & 31 & 0,369230802 & Dez. 2004 & 68 & 0,364091151 \\
\hline Mar. 2004 & 32 & 0,385383267 & Dez. 2004 & 69 & 0,362573895 \\
\hline Abr. 2004 & 33 & 0,386227317 & Dez. 2004 & 70 & 0,363240451 \\
\hline Abr. 2004 & 34 & 0,373341431 & Dez. 2004 & 71 & 0,360099179 \\
\hline Abr. 2004 & 35 & 0,376868071 & Jan. 2005 & 72 & 0,360169813 \\
\hline Abr. 2004 & 36 & 0,376092577 & Jan. 2005 & 73 & 0,358828472 \\
\hline Mai. 2004 & 37 & 0,375094810 & Jan. 2005 & 74 & 0,355533654 \\
\hline Mai. 2004 & 38 & 0,384224866 & Jan. 2005 & 75 & 0,372045036 \\
\hline Mai. 2004 & 39 & 0,379106089 & Jan. 2005 & 76 & 0,364091151 \\
\hline Mai. 2004 & 40 & 0,377961159 & Fev. 2005 & 77 & 0,364101250 \\
\hline Mai. 2004 & 41 & 0,378089375 & Fev. 2005 & 78 & 0,360086867 \\
\hline Jun. 2004 & 42 & 0,371623861 & Fev. 2005 & 79 & 0,352425905 \\
\hline Jun. 2004 & 43 & 0,369196208 & Fev. 2005 & 80 & 0,352832058 \\
\hline Jun. 2004 & 44 & 0,366292972 & Mar. 2005 & 81 & 0,354842260 \\
\hline Jun. 2004 & 45 & 0,367793804 & Mar. 2005 & 82 & 0,343177501 \\
\hline Jul. 2004 & 46 & 0,367769431 & Mar. 2005 & 83 & 0,349907853 \\
\hline Jul. 2004 & 47 & 0,369786010 & Mar. 2005 & 84 & 0,348688803 \\
\hline Jul. 2004 & 48 & 0,372019470 & Abr. 2005 & 85 & 0,350242723 \\
\hline Jul. 2004 & 49 & 0,383059729 & Abr. 2005 & 86 & 0,349969047 \\
\hline Jul. 2004 & 50 & 0,378618337 & Abr. 2005 & 87 & 0,354926771 \\
\hline Ago. 2004 & 51 & 0,354179623 & Abr. 2005 & 88 & 0,345174186 \\
\hline Ago. 2004 & 52 & 0,361294805 & Mai. 2005 & 89 & 0,350216589 \\
\hline Ago. 2004 & 53 & 0,367165827 & Mai. 2005 & 90 & 0,343177501 \\
\hline Ago. 2004 & 54 & 0,368661318 & Mai. 2005 & 91 & 0,352625450 \\
\hline Set. 2004 & 55 & 0,357355599 & Mai. 2005 & 92 & 0,343217306 \\
\hline \multirow[t]{2}{*}{ Set. 2004} & 56 & 0,356474678 & Mai. 2005 & 93 & 0,339040259 \\
\hline & Totak & 13,309533761 & & Total & 13,185186308 \\
\hline \multicolumn{5}{|c|}{ Custo de manutenção por Ave/semana } & 0,358036758 \\
\hline
\end{tabular}

